\title{
REAL-TIME TSUNAMI INUNDATION PREDICTION USING OFFSHORE TSUNAMI OBSERVATION
}

\author{
Daisuke TATSUMI ${ }^{1}$ and Takashi TOMITA ${ }^{1}$
}

\begin{abstract}
The previous real-time tsunami prediction based on the inversion method and the linear superposition can predict the tsunami in near shore area quickly, but it can not predict the tsunami inundation. The present study developed the empirical formula to estimate the overflow rate from the tsunami profile predicted by the previous method. Moreover, the level fill method was applied to predict the tsunami inundation from the estimated overflow rate. Numerical experiments using the actual topography and the historical earthquakes proved that the combination of the previous method, the empirical formula to estimate the overflow rate, and the level fill method can predict the tsunami inundation quickly from the offshore tsunami observation.
\end{abstract}

Keywords: real-time tsunami inundation prediction; GPS buoy; level fill method

\section{INTRODUCTION}

The objective of the present study is to predict the tsunami inundation quickly from the offshore tsunami observation. Together with coastal structures, the real-time tsunami inundation prediction can be an effective countermeasure against tsunami disasters. If the tsunami inundation is predicted before the tsunami arrival, the evacuation of residents and the control of water gates can be operated more securely and effectively.

The authors have already developed the method to predict the tsunami in near shore area quickly from the offshore tsunami observation based on the inversion method and the linear superposition (Tatsumi and Tomita, 2008). However, this method can not predict the tsunami inundation, because the linear superposition is not valid, and the non-linear effect is not negligible for the tsunami inundation.

In the present study, firstly, the empirical formula to estimate the overflow rate from the tsunami profile in near shore area predicted by the previous method is developed. Secondly, the level fill method is applied to predict the tsunami inundation quickly from the estimated overflow rate. Finally, numerical experiments using the actual topography and the historical earthquakes are conducted.

Fig. 1 describes the flowchart of the real-time tsunami inundation prediction proposed in the present paper.

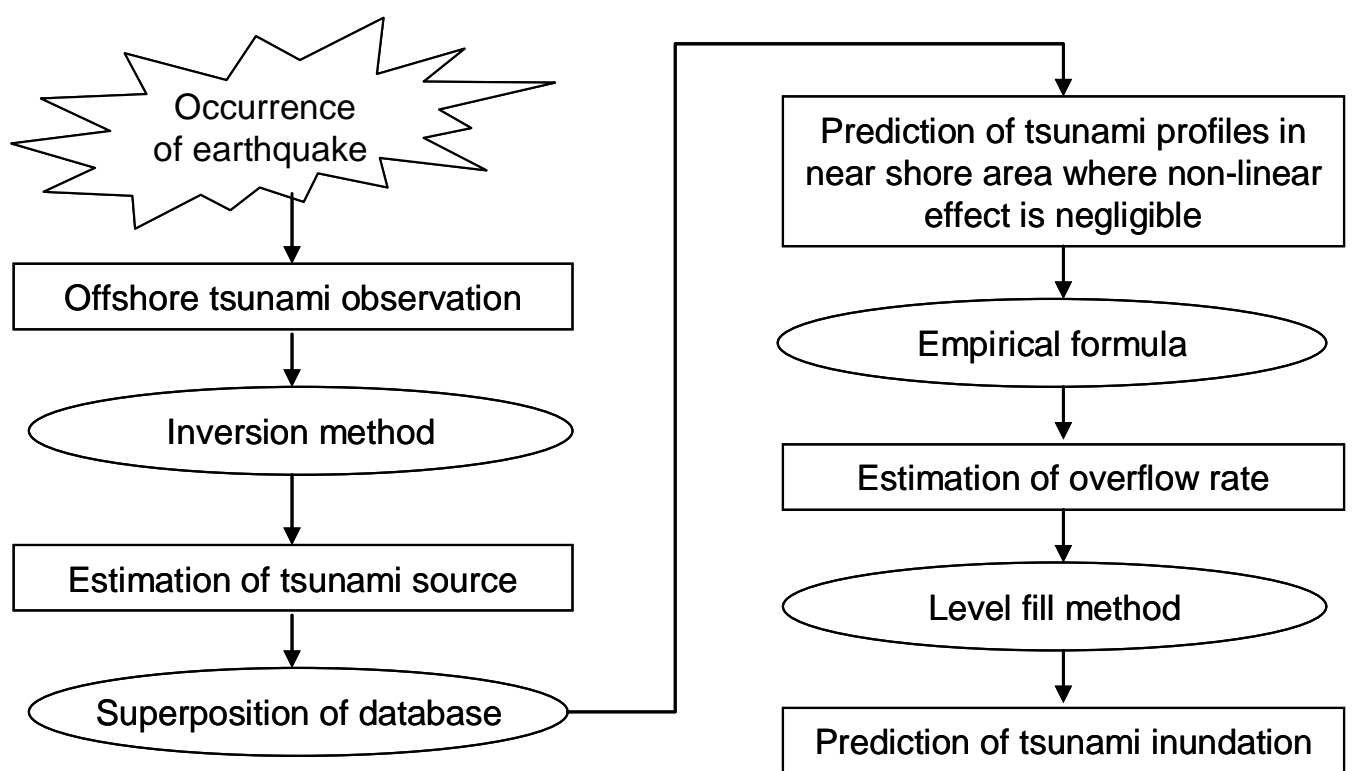

Figure 1. Flowchart of proposed real-time tsunami inundation prediction

\footnotetext{
${ }^{1}$ Asia-Pacific Center for Coastal Disaster Research, Port and Airport Research Institute, 3-1-1 Nagase, Yokosuka, Kanagawa, 239-0826, Japan
} 


\section{METHODOLOGIES FOR REAL-TIME TSUNAMI INUNDATION PREDICTION}

\section{Empirical Formula to Estimate Overflow Rate}

The tsunami predicted by the inversion method and the linear superposition can not consider the non-linear effect and run-up, so the empirical formula described in Eq. 1 is developed. Eq. 1 can estimate the overflow rate per unit width $(q)$ from the amplitude of a rising wave $\left(\eta_{\max }\right)$ and the duration of a rising wave $(T)$ at the coast. $g$ and $z$ denote the gravitational acceleration and the crown height of a seawall respectively. Once the tsunami profile at the coast is predicted by the inversion method and the linear superposition, the overflow rate can be obtained immediately by Eq. 1.

$$
q=\frac{\alpha T}{2}\left(0.35 \sqrt{2 g}\left(\beta \eta_{\max }-z\right)^{1.5}\right)
$$

Assuming that the temporal variation of the overflow rate is the shape of an isosceles triangle, the overflow rate is estimated by the product of the maximum overflow rate and the duration of the overflow (Kato et al., 2007). The estimation of the maximum overflow rate given in the brackets of Eq. 1 is based on the experimental result (Honma, 1940). To convert the duration of a rising wave to the duration of the overflow, the regression coefficient $\alpha$ is used. In addition to $\alpha$, the present study introduces the coefficient $\beta$ for adjusting the difference between the actual tsunami height and the amplitude of the superposed linear tsunami.

\section{Level Fill Method}

Level fill method (Rural Developing Bureau of MAFF et al., 2004) assumes that the inundation height above the mean sea level is the identical value in a catchment area, so the tsunami inundation can be predicted immediately from the estimated overflow rate.

The present study aims to predict the spatial distribution of the maximum inundation depth at the certain time after the occurrence of the earthquake. Thus, the overflow rate estimated by Eq. 1 needs to be modified as described in Eq. 2, because Eq. 1 ignores the undertow from the land to the sea.

$$
Q=\gamma \sum_{i=1}^{n} q_{i}
$$

where $n$ denotes the number of the grids located along the shore line in a catchment area, and $Q$ represents the modified overflow rate which is inputted into the level fill method. The parameter $\gamma$ is introduced to reflect the topographic features of a catchment area.

\section{NUMERICAL EXPERIMENTS}

\section{Outline and Calculation Conditions}

Although offshore tsunami observation such as GPS Buoy is now in practical use (Kato et al., 2005), there is not enough the actual observation data of tsunamis at offshore locations. Thus, numerical experiments are conducted to identify the regression coefficients $\alpha, \beta$, and $\gamma$ and to validate the proposed real-time tsunami inundation prediction. The actual tsunami is substituted by the imaginary observation calculated by the non-linear long wave model considering run-up (Goto and Sato, 1993).

The actual topography of Wakayama Shimotsu Port, Japan is used in this study. Wakayama Shimotsu Port is located near the subduction zone named Nankai Trough and suffered from tsunami disasters many times in the past.

Fig. 2 shows the bathymetry of the calculation domain, the location of Wakayama Shimotsu Port, and the locations of five GPS Buoys. The locations of five GPS Buoys are the same as the actual ones (Ports and Harbous Bureau of MLIT, Website). The size of the calculation domain is $800 \mathrm{~km}$ by 440 $\mathrm{km}$. The spatial resolution varies from $1350 \mathrm{~m}$ to $450 \mathrm{~m}, 150 \mathrm{~m}$, and $50 \mathrm{~m}$ for nesting grids. Time step is set to $1 \mathrm{~s}$.

Fig. 3 describes the topography of Wakayama Shimotsu Port. Black color indicates the places whose ground elevation is over $10 \mathrm{~m}$. The total number of the grids located along the shore line is 495 . According to the calculation results of the historical tsunamis, the assumed maximum tsunami height in this port does not exceed $10 \mathrm{~m}$, so the shore line and the hinterland are divided into five catchment areas based on the contour lines of $10 \mathrm{~m}$ ground elevation.

Fig. 4 indicates the locations and the crown height of coastal structures in the port. 

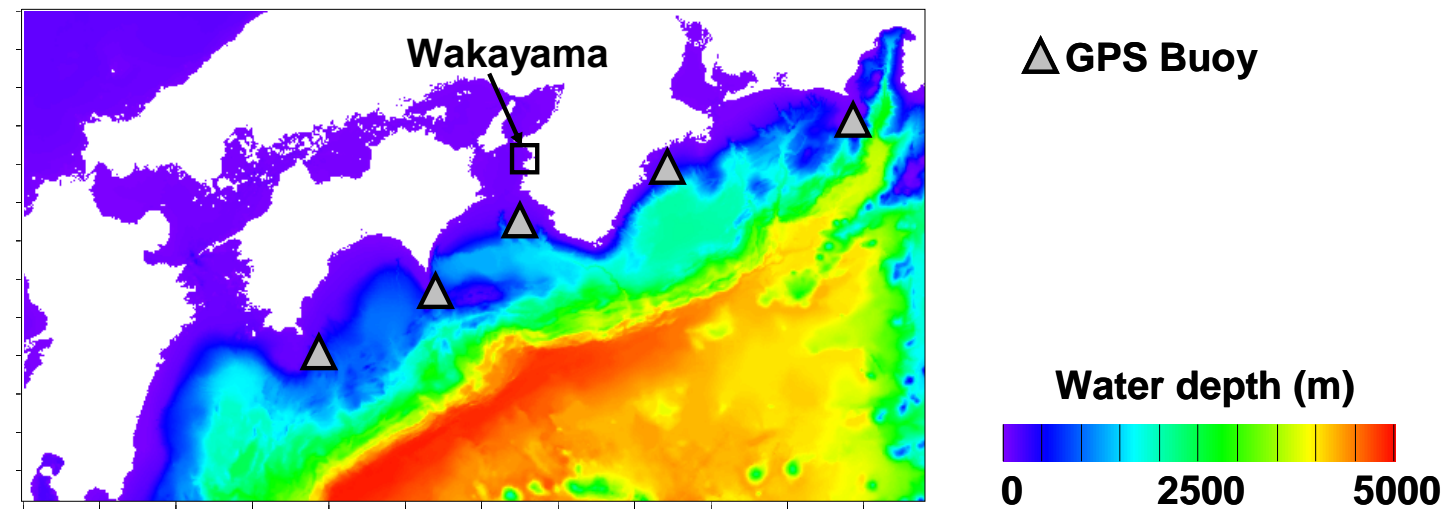

Figure 2. Bathymetry of calculation domain and locations of Wakayama Shimotsu Port and five GPS Buoys

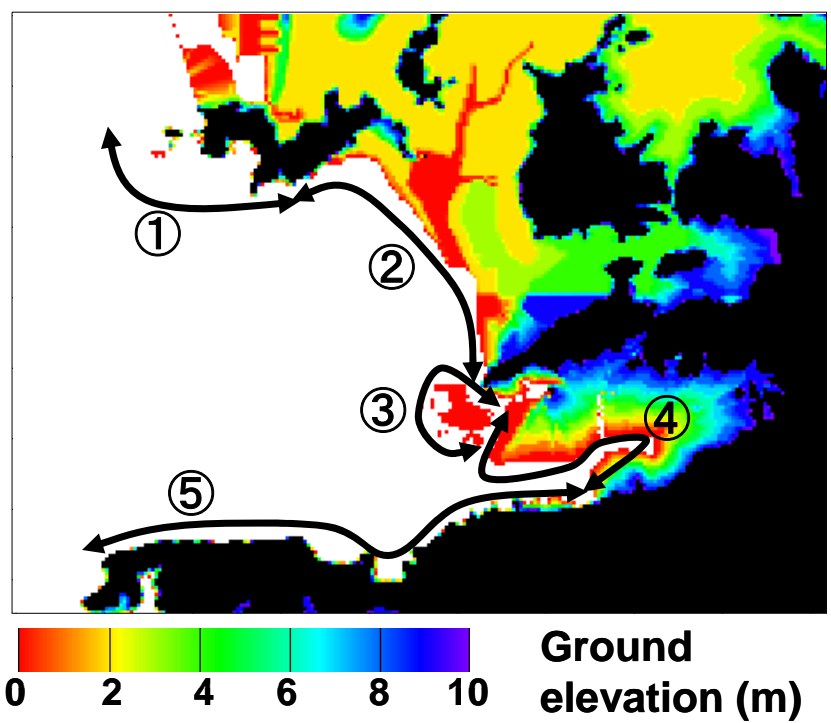

Figure 3. Topography of Wakayama Shimotsu Port and locations of five catchment areas
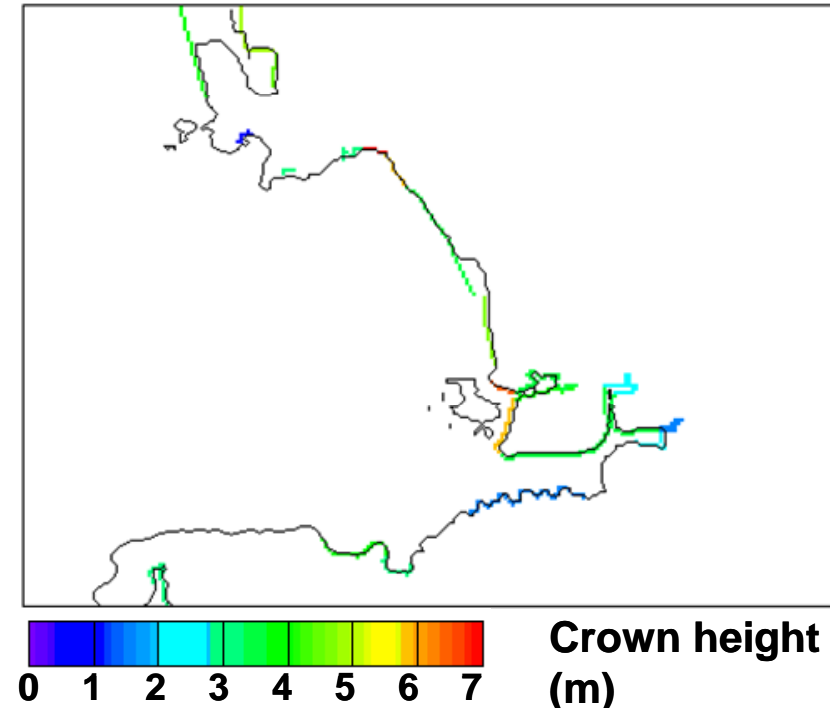

Figure 4. Crown height of coastal structures in Wakayama Shimotsu Port 


\section{Identification of Parameters}

The parameter identification for $\alpha, \beta$, and $\gamma$ is conducted by comparing the calculation results of two numerical models. One model is the non-linear long wave model considering run-up, which can reproduce the actual tsunami. The other model is the linear long wave model considering reflective boundary condition at the coast, which can reproduce the near shore tsunami predicted by the inversion method and the linear superposition.

As the incident waves, sinusoidal waves with various amplitudes and wave periods described in Table 1 are generated at the west or the south open boundary surrounding Wakayama Shimotsu Port. The total number of the calculation cases is 48 .

\begin{tabular}{|l|c|}
\hline \multicolumn{2}{|c|}{ Table 1. Properties of sinusoidal incident waves } \\
\hline Amplitude $(\mathrm{m})$ & $0.5,1.0,1.5,2.0,2.5,3.0$ \\
\hline Wave period $(\mathrm{min})$ & $5,10,20,30$ \\
\hline Wave direction & From the west or the south open boundary \\
\hline
\end{tabular}

The superposed linear tsunami assumes the reflect boundary condition at the coast, so the amplitude of the superposed linear tsunami can be at most twice as high as the actual tsunami height due to the generation of a standing wave. Therefore, the parameter $\beta$ is supposed to be between 0.5 and 1.0. Firstly, $\beta$ is varied from 0.5 to 1.0 with 0.1 interval, and the parameter $\alpha$ is identified for each $\beta$ with least squares method. Then, the optimized set of $\alpha$ and $\beta$ is identified by maximizing the coefficient of determination.

$\alpha$ and $\beta$ are required at every grid located at the shore line, so 495 sets of $\alpha$ and $\beta$ are identified. The averages of the identified $\alpha$ and $\beta$ are 0.28 and 0.73 respectively. It is natural that the identified $\alpha$ is less than 1.0, because the duration of the rising wave of the superposed linear tsunami tends to be larger than the duration of the overflow of the actual tsunami.

Fig .5 describes the estimation results of the overflow rate at 495 locations along the shore line for 48 kinds of sinusoidal waves. Dots on the solid line mean that the estimated overflow rate equals to the imaginary observed overflow rate. Dashed lines indicate $\pm 50 \%$ error. It is found that Eq. 1 and the identified sets of $\alpha$ and $\beta$ can estimate the overflow rate almost within $50 \%$ error.

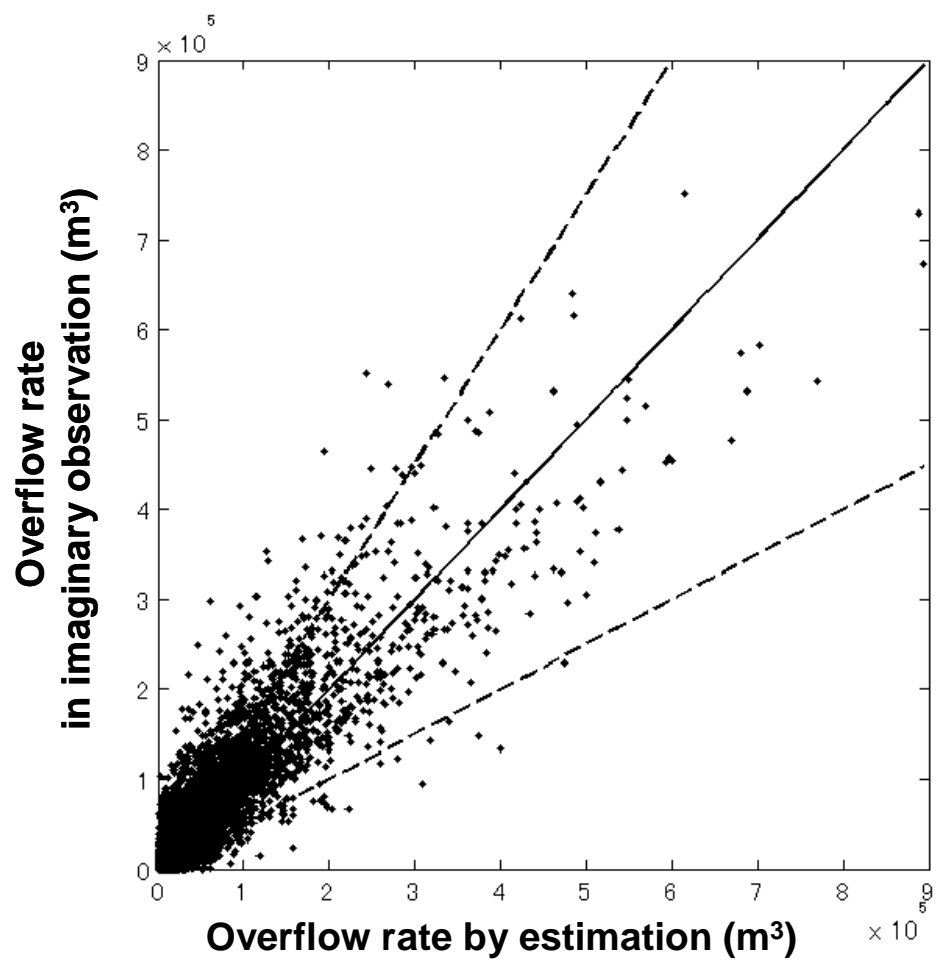

Figure 5. Estimation of overflow rate (Dashed lines indicate $\pm 50 \%$ error) 
After identifying $\alpha$ and $\beta$, the parameter $\gamma$ is identified by comparing the inundation volume of the actual tsunami and the sum of the overflow rate calculated by Eq. 2 with least squares method. $\gamma$ is required at each catchment area, so five $\gamma$ from the catchment area 1 to the catchment area 5 are identified as follows: $0.20,0.92,0.23,0.55$, and 0.25 .

As an example of the prediction of the inundation volume from the sum of the overflow rate, the prediction result for the catchment area 4 is described in Fig. 6. The imaginary observed inundation volume is proportional to 0.55 time of the sum of the estimated overflow rate almost within $50 \%$ error. Fig. 6 proves that Eq. 2 and the identified $\gamma$ can predict the inundation volume.

In addition, Fig. 7 shows the prediction results of the inundation area by the level fill method for 48 kinds of sinusoidal waves. Circles on the solid line mean that the predicted inundation area equals to the imaginary observed inundation area. Dashed lines indicate $\pm 50 \%$ error. It is found that the level filled method can predict the inundation area almost within $50 \%$ error.

However, it should be noted that the predicted inundation area is likely to be larger than the imaginary observed inundation area. It is because the criteria in the level fill method to determine whether a place is inundated or not is only the ground elevation of the place. Even if some places with low ground elevation are located far from the coast, the level fill method still determines that these places are inundated quickly.

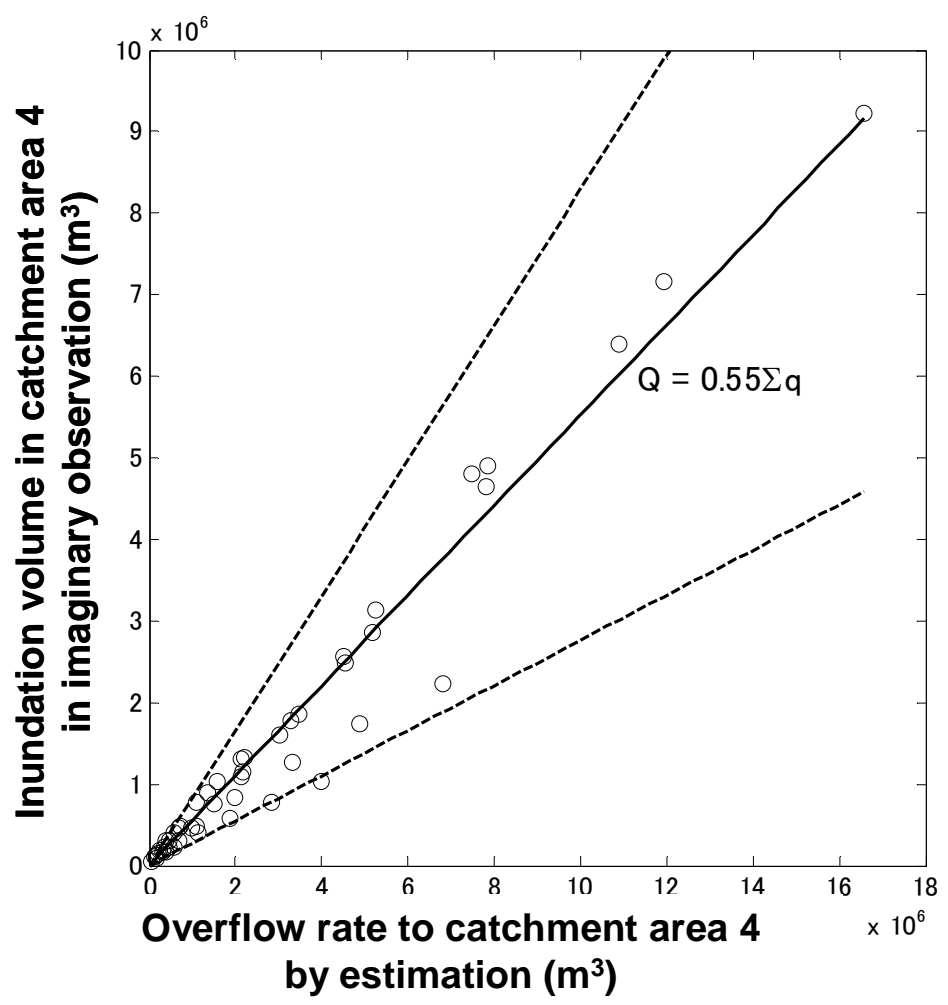

Figure 6. Prediction of inundation volume in catchment area 4 (Dashed lines indicate $\pm \mathbf{5 0} \%$ error) 


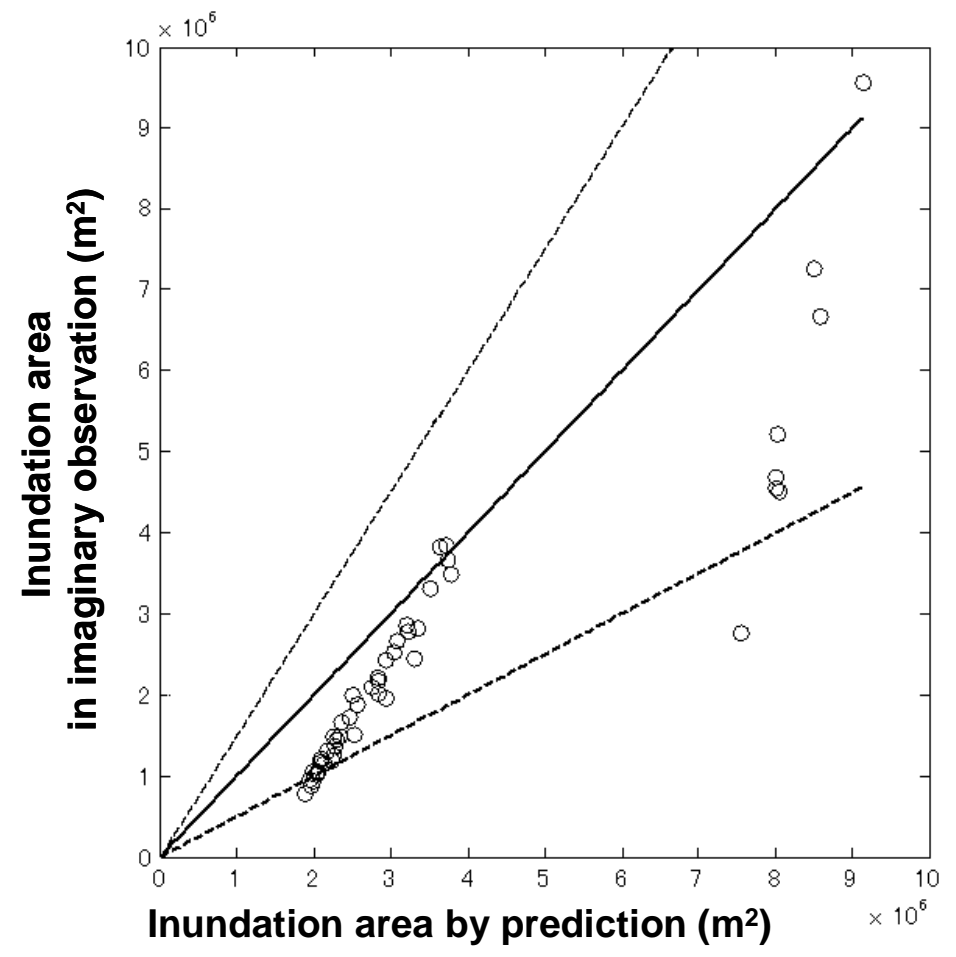

Figure 7. Prediction of inundation area (Dashed lines indicate $\pm \mathbf{5 0} \%$ error)

Validation of Real-time Tsunami Inundation Prediction Using Historical Earthquakes

In order to validate whether the proposed real-time tsunami inundation prediction can predict the inundation quickly from the tsunami profiles observed at offshore locations, the developed method is applied to the two historical earthquakes in Table 2.

\begin{tabular}{|l|c|c|c|c|}
\hline \multicolumn{5}{|c|}{ Table 2. Basic information of two historical earthquakes (Sato, 1989) } \\
\hline Name & Year & Magnitude & Location & Depth $(\mathrm{km})$ \\
\hline Hoei & 1707 & 8.4 & $33.2 \mathrm{~N}, 135.9 \mathrm{E}$ & $\mathrm{n} / \mathrm{a}$ \\
\hline Nankai & 1946 & 8.0 & $33.03 \mathrm{~N}, 135.62 \mathrm{E}$ & 20 \\
\hline
\end{tabular}

Based on the fault parameters (Sato, 1989), the imaginary observation for the tsunami profiles at five GPS Buoys and the inundation in Wakayama Shimotsu Port is reproduced by the non-linear long wave model considering run-up. The locations of the calculation domain, five GPS Buoys, and Wakayama Shimotsu Port are described in Fig. 2. Five GPS Buoys are located at around $20 \mathrm{~km}$ off the coast and at the same places as the actual ones.

Tatsumi and Tomita (2008) inputs the observed tsunami profiles for 15 minutes after the occurrence of the earthquakes at five GPS Buoys to the inversion method and predicts the tsunami arrival time and the first tsunami height in near shore area. Therefore, the present study also uses the tsunami profiles observed at five GPS Buoys for 15 minutes after the shocks. The calculation time required for the real-time tsunami inundation prediction is a couple of minutes, so the inundation prediction can be completed within 20 minutes after the occurrence of the earthquakes.

Moreover, due to the short observation period inputted into the inversion method, the prediction error for the following tsunami waves after the first tsunami wave is relatively large. Thus, the prediction target of the present study is the maximum tsunami inundation depth up to two hours after the shocks, because the tsunami inundation in Wakayama Shimotsu Port is affected dominantly by the first tsunami wave up to two hours after the occurrence of the earthquakes.

Fig. 8 shows the estimation result of the initial water surface elevation of 1946 Nankai Earthquake. Fig. 9 shows the prediction results of the tsunami profiles at Wakayama's nearest GPS Buoy (top), outside of Wakayama Shimotsu Port (middle), and inside of the port (bottom) for 1946 Nankai Earthquake respectively. As mentioned above, due to the short observation period inputted into the inversion method, the initial water surface elevation can not be fully estimated, and the prediction error 
for the following tsunami waves after the first tsunami wave is relatively large. However, the tsunami arrival time and the first tsunami height outside of the port can be predicted with good accuracy. The tsunami arrives at Wakayama Shimotsu Port 40 to 50 minutes after the shock, so the tsunami inundation prediction can be completed before the tsunami arrival. The prediction result based on the linear superposition ignores run-up and non-linear effect, so the predicted tsunami profile inside of the port shows a discrepancy with the imaginary observed tsunami profile. In order to adjust this discrepancy and to estimate the overflow rate from the linear superposed tsunami, Eq. 1 and Eq. 2 are developed.

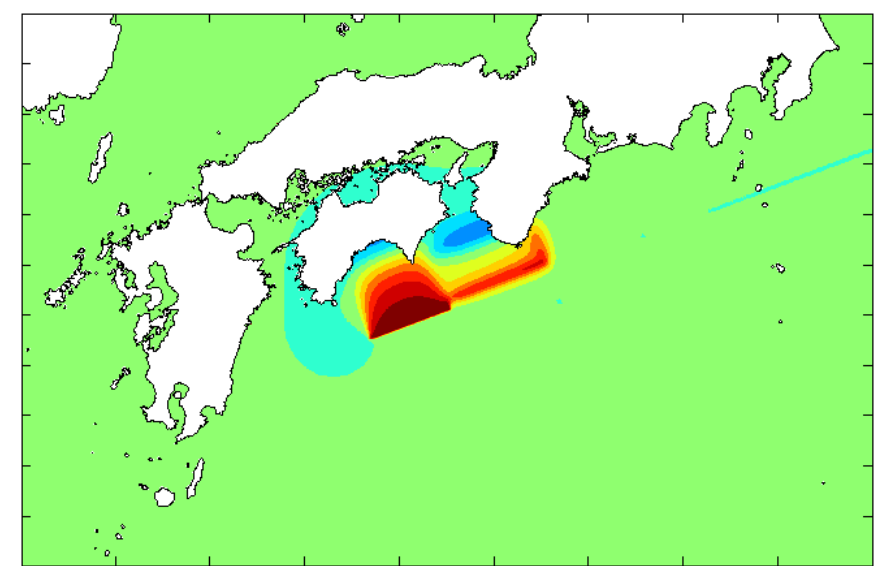

(m)

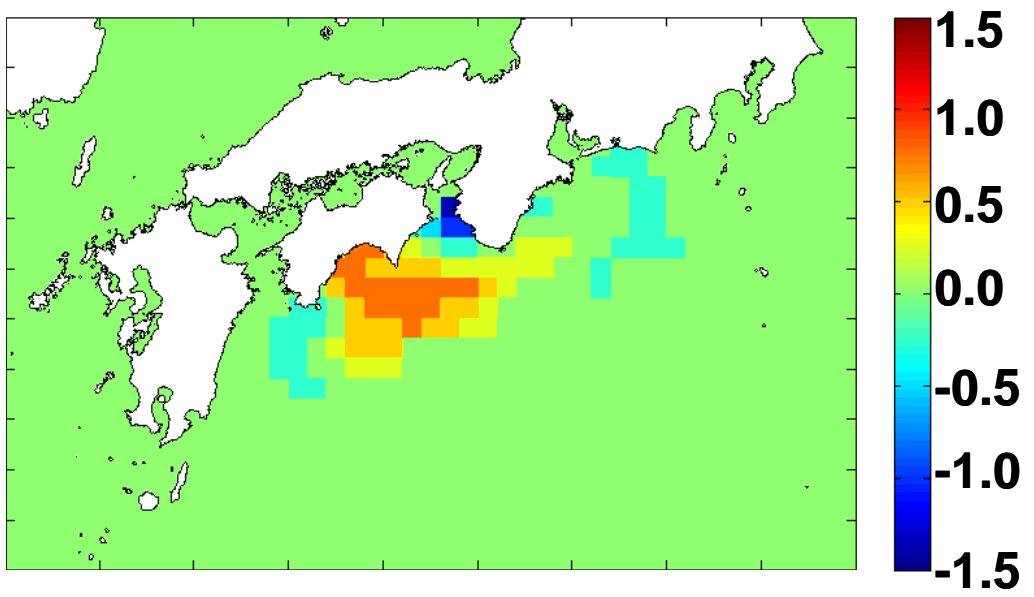

Figure 8. Estimation result of initial water surface elevation of 1946 Nankai Earthquake (Upper: imaginary observation, Lower: estimation) 

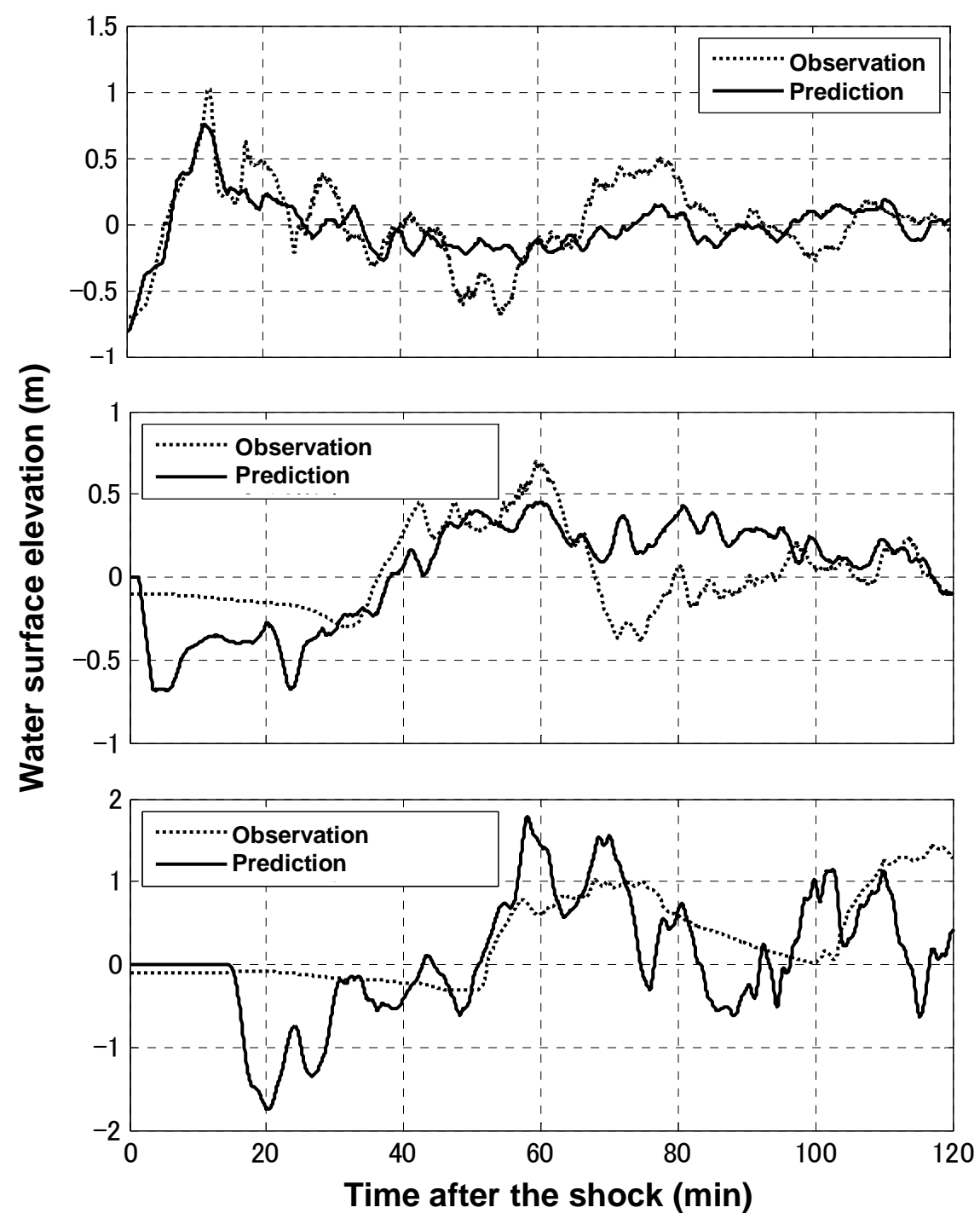

Figure 9. Prediction results of tsunami profiles for 1946 Nankai Earthquake (Top: at Wakayama's nearest GPS Buoy, Middle: outside of Wakayama Shimotsu Port, Bottom: inside of Wakayama Shimotsu Port)

Table 3 shows the prediction results for the tsunami inundation up to two hours after the occurrence of 1707 Hoei Earthquake and 1946 Nankai Earthquake respectively. The accuracy of the prediction is evaluated by three indexes of the inundation volume, the inundation area, and the maximum inundation depth. The percentiles in brackets indicate the ratio of the prediction values to the imaginary observation values.

It is found that the tsunami inundation can be predicted almost within $50 \%$ error by the proposed method. However, as mentioned in the previous section, the inundation volume and the inundation area tend to be overestimated, and, on the contrary, the maximum inundation depth is likely to be underestimated by the prediction.

Fig. 10 describes the comparison between the imaginary observation and the prediction of the maximum inundation depth caused by 1946 Nankai Earthquake. The spatial distribution of the predicted maximum inundation depth is consistent with that of the imaginary observation, although there are some discrepancies between the imaginary observation and the prediction.

Firstly, the place A in Fig. 10, which is located far from the coast, is wrongly determined to be inundated. It is because the ground elevation of the place A is very low, and the level fill method can not consider the distance between the place and the coast. Secondly, the maximum inundation depth of the place $B$, which is located in front of a hill, is underestimated. It is because the level fill method can not consider the accumulation of water volume and run-up phenomena in front of a hill. Instead, if the ground elevation behind the hill is low, such places behind the hill are determined to be easily 
inundated. Thirdly, the wharf $\mathrm{C}$, which is surrounded by the coastal structures and is included in the catchment area 4, is wrongly determined to be inundated. It is because once the overflow occurs at the other places than the wharf $C$ in the catchment area 4, the overflowed tsunami is determined to inundate the lower places by the level fill method. Even though the wharf $\mathrm{C}$ is protected by the coastal structures, the ground elevation of the wharf $\mathrm{C}$ is lower than the other places in the catchment area 4, so the wharf $\mathrm{C}$ is determined to be easily inundated.

The reasons of the overestimation of the inundation volume and the inundation area and the underestimation of the maximum inundation depth are thought to be these problems of the level fill method.

\begin{tabular}{|l|c|c|c|c|}
\hline \multicolumn{5}{|c|}{ Table 3. Results of tsunami inundation prediction } \\
(Percentiles in brackets indicate ratio of prediction to imaginary observation) \\
\hline Earthquake & Imaginary observation & \multicolumn{2}{|c|}{ Prediction } \\
\hline Inundation volume $\left(\mathrm{m}^{3}\right)$ & Hoei & Nankai & Hoei & Nankai \\
\hline Inundation area $\left(\mathrm{m}^{2}\right)$ & $2,920,088$ & $2,384,375$ & $\begin{array}{c}3,790,562 \\
(129.8 \%)\end{array}$ & $\begin{array}{c}3,927,159 \\
(164.7 \%)\end{array}$ \\
\hline Maximum inundation depth $(\mathrm{m})$ & $2,452,500$ & $2,077,500$ & $\begin{array}{c}3,107,500 \\
(126.7 \%)\end{array}$ & $\begin{array}{c}3,160,000 \\
(152.1 \%)\end{array}$ \\
\hline
\end{tabular}

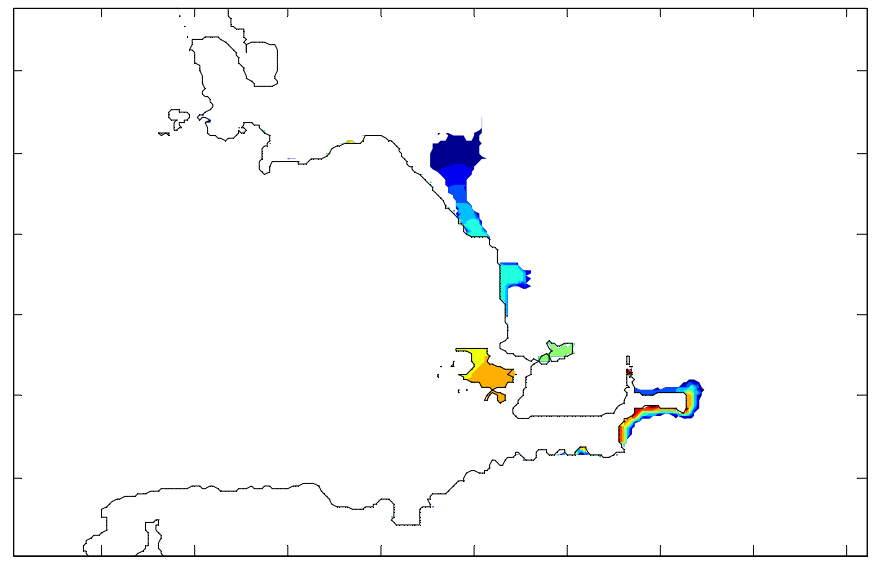

(m)

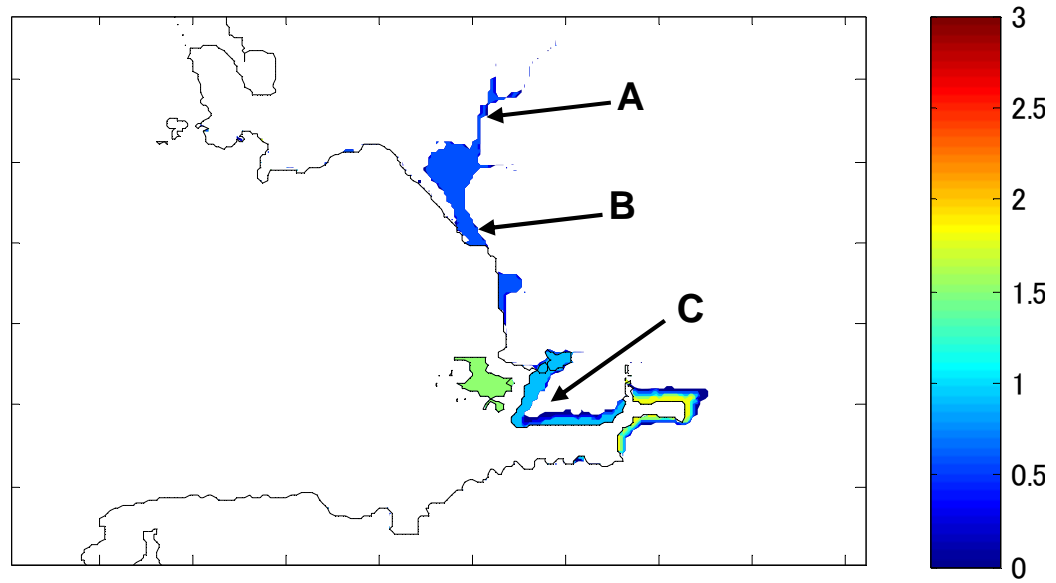

Figure 10. Prediction of maximum inundation depth up to two hours after the occurrence of 1946 Nankai Earthquake (Upper: imaginary observation, Lower: prediction) 


\section{CONCLUSIONS}

Real-time tsunami inundation is developed by the combination of the inversion method, the linear superposition, the empirical formula to estimate the overflow rate, and the level fill method. The calculation time required for the proposed method is a couple of minutes. In the numerical experiments using the actual topography and the historical earthquakes, the proposed method can predict the tsunami arrival time, the first tsunami height, and the tsunami inundation in 20 minutes after the shock based on the 15 minutes tsunami profiles at five GPS Buoys.

However, the criteria in the level fill method to determine whether a place is inundated or not is only the ground elevation of the place. Therefore, the prediction results are likely to overestimate the inundation volume and the inundation area and tend to underestimate the maximum inundation depth.

\section{ACKNOWLEDGMENTS}

We would like to express our gratitude to Marine Information Group of Port and Airport Research Institute for providing the information on GPS Buoy. This research is partially supported by the Ministry of Education, Science, Sports, and Culture of Japan, Grant-in-Aid for Scientific Research (S), 21221007.

\section{REFERENCES}

Goto, C. and K. Sato. 1993. Development of tsunami numerical simulation system for Sanriku Coast in Japan, Report of the Port and Harbour Research Institute, Vol.32, No.2, 44 p. (in Japanese).

Honma, H. 1940. Coefficient of flow volume on low overflow weir, Civil Engineering, JSCE, Vol.26-6, pp.635-645 (In Japanese).

Kato, F., M. Fukuhama, H. Fujii, T. Takagi, and T. Kodama. 2007. An effective tsunami damage estimation method considering dike height, Annual Journal of Coastal Engineering, JSCE, Vol.54, pp.261-265 (in Japanese).

Kato T., Y. Terada, K. Ito, R. Hattori, T. Abe, T. Miyake, S. Koshimura, and T. Nagai. 2005. Tsunami due to the 2004 September 5th off the Kii peninsula earthquake, Japan, recorded by a new GPS buoy, Earth ,Planets, and Space, Vol. 57, pp. 297-301.

Ports and Harbours Bureau of Ministry of Land, Infrastructure, Transport and Tourism. Website. Nationwide Ocean Wave Information Network for Ports and Harbours, http://nowphas.mlit.go.jp/index.html (in Japanese).

Rural Development Bureau and Fisheries Agency of Ministry of Agriculture, Forestry and Fisheries, and River Bureau and Ports and Harbours Bureau of Ministry of Land, Infrastructure, Transport and Tourism. 2004. Guidelines of Cost Benefit Analysis for Coastal Projects, pp.33-48 (in Japanese).

Sato, R. 1989. Handbook of Earthquake Fault Parameters in Japan, Kajima Institute Publishing Co., Ltd., pp.126-127 and p.210 (in Japanese).

Tatsumi, D., and T. Tomita. 2008. Improvement of real-time tsunami prediction based on inversion method by using earthquake information, Proceedings of 31st International Conference on Coastal Engineering, ASCE, pp.1409-1420. 